quantity. She had at no time suffered from any pain in the loins, but her friends said that for the last year she had been noticed to walk with her hand on her left hip so as to support that side. On June 23rd she passed only a very small quantity of urine and she was sick in the evening. On the 24th she was seen by Dr. Fraser, who drew off about half an ounce of urine from the bladder; there was at this time a little pain in the left loin. Diuretic and diaphoretic treatment was adopted, with hot applications to the loins, but without any result, as the bladder remained empty and she gradually became more and more drowsy. When the patient was seen by Mr. Parkin on June 28th she was very drowsy, but she could be roused to answer questions in a feeble voice. She complained of feeling rery weak. The tongue was furred but not dry, the temperature was normal, and the pulse was 84 , full and strong. She had no twitchings or sickness, and no pain, but on deep pressure in the left loin there was decided tenderness. No tumour was to be felt in either loin, but the ribs were so close to the iliac crest that manipulation was very difficult. Per vaginam the atrophied uterus was drawn over to the left side by old cellulitis. No calculus was to be felt in the vreter and the bladder was quite empty. As the anuria had then (June 28th) lasted for five days it was decided to explore the left renal region, the few symptoms which were present indicating this side as being the affected wne. The usual oblique incision was made after the patient alad been anæsthetised by a mixture of ether and chloroform, which was given by Dr. Fraser. The kidney was found to be dark in colour and hard, as if distended, and it was estimated to be about eight inches in length. When it was incised along the dorsal border about six ounces of urine ascaped, the last portion to come away being mixed with some pus. The pelvis on exploration by the finger was found to be enlarged, the pyramids were flattened, and the finger was only with difficulty worked into the ureter on account of the existence of a spur-like projection at its sunction with the infundibulum. A flexible probe was passed gently down the ureter as far as the brim of the pelvis, but no stone could be felt, nor could calculus be detected by malpating the renal substance with the finger in the pelvis of the kidney. The bleeding from the wound of the kidney was very free, but it was easily controlled by a suture passed through the renal substance. A drainage-tube was inserted into the pelvis and brought out at the loin. The wound was rapidly sewn up with a continuous suture, and the collapse, which was considerable, treated by warmth and by the injection of a pint of hot water with a little irandy into the rectum. The progress of the patient was most satisfactory. The alarming symptoms-muscular prostration and drowsiness-disappeared in twenty-four hours ; there was a most abundant excretion of urine from the loin, estimated by weighing the pads applied to the wound at over $40 \mathrm{oz}$. in the twenty-four hours, and the temperature only once rose above normal, on that occasion jeing $100^{\circ} \mathrm{F}$. The wound healed by primary intention and the sutures were removed on the eighth day. About one ounce of urine was withdrawn from the bladder on the same day, and subsequently the patient on two occasions passed about two ounces herself. At the date of writing the bulk of the urine is passed through the lumbar sinus into a urinal. The patient is able to come downstairs and for her age is in a good state of health.

Resarks. - The symptoms in this case were typical of obstructive anuria as described by Sir William Roberts. : The asual difficulty in such cases at once arose-viz, as to the side of the obstruction, and then came the question what had become of the other kidney-was it atrophied or was there reflex suppression, the kidney itself being healthy ? The only symptoms were, firstly, a history of some old trouble in the left loin, which was evidenced by the patient supporting that side when walking; and, secondly, deep-seated tenderness in that loin on examination. There was very little evidence pointing to a renal calculus and there was no palpable tumour. In a condition so obscure, the fact that there was no symptom whatever of any affection of the right kidney was a strong argument in favour of there being something amiss with the left, and this view of the case was confirmed at the operation. The left kidney was distended and was undoubtedly hypertrophied, the cortex being at least an inch and a quarter in thickness, and this, with the subsequent course of the case, indicated that the right kidney was either absent or atrophic, but, if the latter, it was not possible to give any definite reason for the atrophy.

There are two riews $t$ ) account for the anuria; firstly, that the left ureter had been gradually blocked by the contraction following the old pelvic cellulitis; and, secondly, that the left kidney had hypertrophied to compensate for the absence of the right, and that, as the surrounding fat had become absorbed through advancing age, it had first become mobile, then hydro-nephrotic to a slight extent, and finally that its ureter had become kinked at the infundibulum. This latter view seems to be the more probable one, and it is supported by the finding of a sort of spur at the operation. The dilata. tion of the renal pelvis and of the calices, with the flattening of the pyramids, indicated that the process of distension had been taking place for some time before the actual kinking of the ureter occurred. This case adds one more to the list of recoveries which have been recorded by Lucas, F. Lange, Bardenheur and Meyer, and it can only be said that an operation which can save a patient from certain death at the age of seventy-four is a most justifiable measure. Recovery with a lumbar fistula may be regarded by some as being undesirable, but a urinary fistula is surely preferable to an artificial anus, and in this case there is still a hope that the urine may ultimately pass down the ureter as the fistula gradually contracts. Hull.

\section{A CASE OF SARCOMA OF THE ORBIT.}

By W. J. COLLINS, M.D., M.S., B.Sc. LoND, F.R.C.S., ASSISTANT SURGEON TO THE ROYAL EYE HOSPITAL, SOUTHWARK.

A MARRIED MAN forty-eight years of age was admitted into the Royal Eye Hospital, Southwark, on March 10th of this year. His left eyeball was displaced upwards and outwards, and its movements were restricted-especially in an inward direction. There was a marked swelling below and to the inner side of the displaced globe, occupying an area of one inch by half an inch. It was softish, semi-elastic and non-fluctuating, and it was distinct from the maxillary margin of the orbit. The ocular conjunction over it was injected and chemosed; it was thrown into prominent folds and was apparently infiltrated. There was a second similar swelling above and to the inner side of the eyeball, lying just under the orbital margin of the frontal bone, and it measured three-quarters of an inch by a quarter of an inch. The conjunctiva over it was not altered, except for some injection. Neither swelling was tender, and at the time of admission they caused the patient no pain. There was epiphora, but there was no nasal obstruction or any depression of the palate. The temperature was normal. There was some impairment of vision and he was unable to read more than $\frac{6}{12}$, although with $+2 \cdot 50 \mathrm{D}$ sph. he could read $\mathrm{J} 1$. The fellow eye read \&. There was no syphilitic history or history of tumours in members of his family. He had always been a healthy man, but thought that he had lost flesh during the previous three or four months. The history he gave was that three months previously he began to suffer from pain over the left eyebrow, the pain increasing when he looked to the left. Three weeks before admission the left eye became red and he commenced to have epiphora, and a fortnight before the swelling appeared quite suddenly - in his own words, "ccming on all at once "- and it had rapidly increased in size since. As the swelling appeared the pain left him. On March 14th, the patient being under A.U.E. mixture, I, to commence with, made an exploratory incision into the larger swelling and, finding it definitely of a solid nature, proceeded first to remove the eyeball and then to thoroughly clear out the orbit. The tumour appeared to grow from the region of the lacrymal sac. The floor and inner wall of the orbit were cleared with the elevator right down to the bone, special attention being paid to the inner canthus, and portions of the upper and lower eyelids were cut away. Chloride of zinc paste, made up with opium, was applied on lint, so as to act thoroughly upon the whole raw and bone surfaces. The pain after the operation was relieved by hypodermic injections of morphia. The chloride of zinc paste was removed on the third day. He was allowed to get up for a little while on the eighth day, having had no bad symptoms. The temperature did not rise above $100 \cdot 4^{\circ} \mathrm{F}$. on the three days after the operation, and since then it had been normal. The paste caused, as usual, a certain amount of sloughing of the soft parts around. The dressing consisted of dry cyanide gauze, which was dusted with iodoform, and salicylic wool; and the orbit was gently 
irrigated with a 1 in 60 carbolic solution. Later, when the greater part of the sloughs had come away, the surface was dressed with cyanide ointment, under which healing at the margins took place very well. His weight was periodically taken and showed a gradual and steady increase until June 21st. The lacrymal bone and the os planum of the ethmoid had come away at this date, but not the orbital

\section{Fig. 1.}

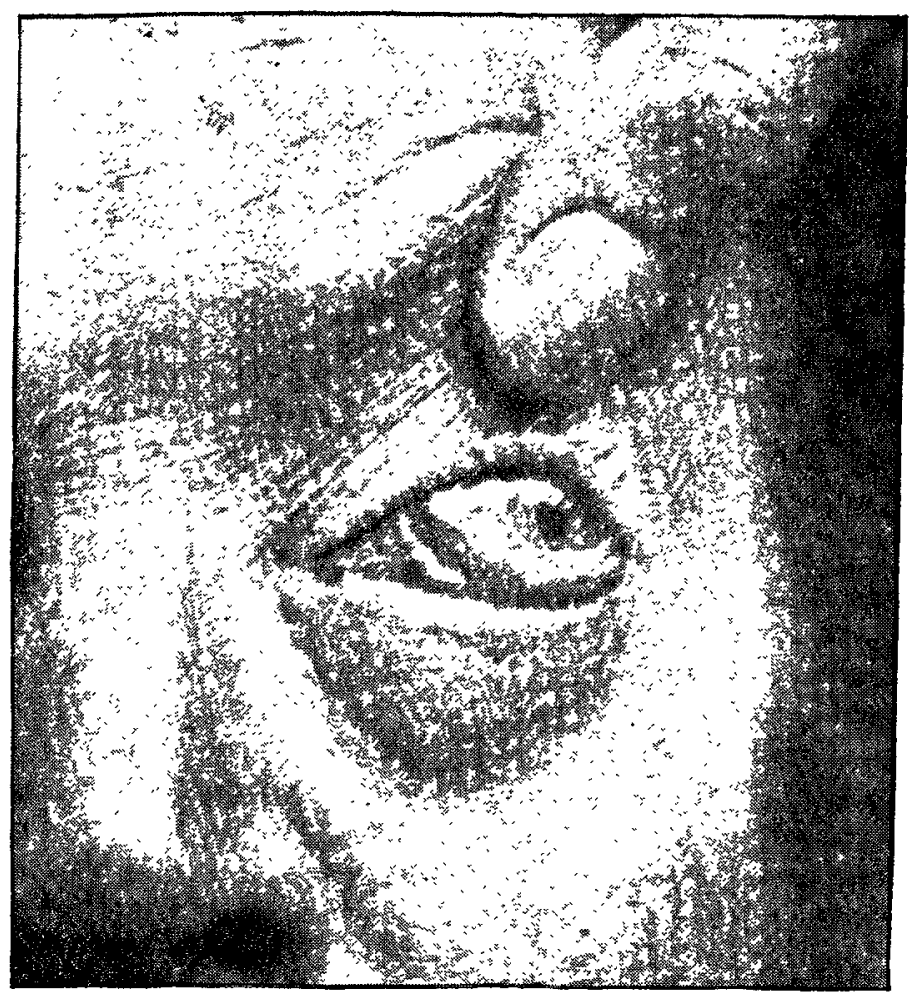

Before operation.

plate of the superior maxilla. There is no evidence of any recurrence and the patient is in a very good state of health. Microscopical examination showe $\mathrm{l}$ the tumour to be a roundcelled sarcoma. The conjunctica was infiltrated, but the eyeball was unaffected.

Remas.ks. - The case was one of extra-ocular intra-orbital

FIG. 2.

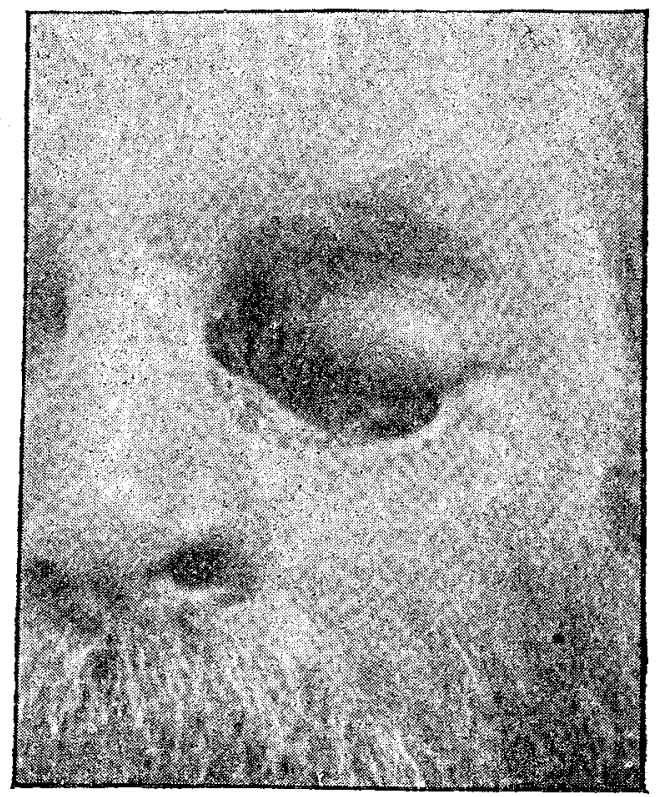

After operation.

sarcoma. It was round-celled and was growing rapidly, though it had not when it was seen invaded any neighbouring cavity. The originating tissue is doubtful. It may have been the orbital connective tissue, as has been described by Virchow in many cases, or the periosteum in the neighbourhood of the lacrymal groove. The complete evacuation of the orbit down to the bones composing it was effected by strong blunt-pointed scissors and an elevator. It was thought to be unwise to attempt to preserve any conjunctiva and it was practically impossible with an adequate use of caustic to save the lids in such cases. The notes of the case and the photographs were taken by Mr. L. V. Cargill, house surgeon.

P.S. - Since writing the above I have had a case very similar to this at the London Temperance Hospital in a girl aged fifteen. It had a history of three months' growth, and an excised portion showed round-celled sarcoma. I evacuated the orbit in a similar manner, but managed to save the eyelids by wrapping them in lint well greased with iodoform ointment. There is anæsthesia over the supra-orbital and supra-maxillarg regions. The temperature has not been above $100^{\circ} \mathrm{F}$.

\section{CASE OF ACUTE INTESTINAL ABSCESS; LAPAROTOMY ; RECOVERY.}

BY BRIGADE-SURGEON ALFRED F. S. CLARKE, M.D. ST. AND., M.R.C.S. ENG.,

SURGEON, ROYAL MILITARY COLLEGE, SANDHURST.

A CADET aged twenty was admitted into the Royal Military College Hospital on Feb. 24th of this year, suffering from severe and sudden pain in the abdomen, with a certain amount of shock. He had been quite well until noon that day, when at Fortification drill he lifted a heavy weight and felt he had somehow strained himself. Pain came on almost at once; in a few hours he was unable to move and he was conveyed on a stretcher to the hospital. He vomited twice during the evening and was thirsty, his pulse being 100 and the temperature $98.6^{\circ} \mathrm{F}$. He complained of difficulty of breathing, and referred the pain chiefly to the right iliac region. Fomentations with turpentine were applied and be was given beef-tea, milk and ice and a hypodermic injection of morphine at 9 P.M. He was a strong and active lad, fond of athletics and swimming, and had previously enjoyed excellent health. Eighteen months ago he had a slight attack of peritonitis at school caused by a "strain " at football, from which, however, he completely recovered. For the next three days his symptoms pointed to intestinal obstruction with some general peritonitis. The temperature rose to $100 \cdot 2^{\circ} \mathrm{F}$., the pulse quickened, the tongue became dry and coated, he vomited four or five times in the twenty-four hours, the abdomen became rigid, tense and distended, and there was no action of the bowels in spite of enemas of warm water with olive and castor oil. The abdominal pain continued to be as severe as it was on admission. He was given small quantities of iced milk or beef-tea, and morphine was injected night and morning. on the 27th he passed a large clay-coloured motion and the symptoms improved. On the 28th a dose of calomel and colocynth was followed by three actions, and a general improvement in all the symptoms took place. On March 6th he was notso well, the vomiting returned, the abdomen became distended, painful and tympanitic, the bowels did not act, and an enema given by a long tube had no effect; he was losing strength and becoming restless and hectic. By the evening of the 7th Surgeon-Major Stock and myself agreed that a laparotomy would be advisable, and Mr. Bruce-Clarke was summoned and kindly came at once. He concurred in the advisability of an abdominal section, and at 3 P.M. he performed laparotomy in the middle line, the patient being anæsthetised with the A.C.E. mixture. After the peritoneum was opened very offensive pus in considerable quantity was found on the right side the intestines were much matted together, the portion exposed being of a dark red colour. Free irrigation of hot water at a temperature of $105^{\circ} \mathrm{F}$. was employed, several gallons being injected with a syphon tube. Pus was found in two or three places. The intestine was opened and stitched to the peritoneum and skin, forming an artificial anus; small rubber tube was inserted. A second and smaller opening was made on the rigbt side and a glass tube was introduced. Iodoform and carbolic gauze and wool were applied to the wound, from which some flatus and a little fæcal matter escaped. Morphine (one-third of a grain) was injected, all food was withheld and three ounces of hot water were given in teaspoonful doses for the first twenty-four hours. He slept well, the temperature fell during the next day to $984^{\circ} \mathrm{F}$., thin fæcal matter flowed freely from the bowel wound, there were much 